\title{
Automating Concrete Construction: Sustainable social housing in Colombia
}

XXIV International Conference of the Iberoamerican Society

\author{
Eduardo Costa \\ University of Bath | United Kingdom | ec977@bath.ac.uk \\ Paul Shepherd \\ University of Bath | United Kingdom | p.shepherd@bath.ac.uk \\ Rodrigo Velasco \\ Universidad Piloto de Colombia | Colombia | rodrigo-velasco@unipiloto.edu.co \\ Roland Hudson \\ Lacunae | United Kingdom | hudson@lacunae.io
}

\begin{abstract}
The construction industry is a major source of carbon, and the main culprit is concrete. In addition, productivity for the construction sector is poor, and concrete construction in particular is labour intensive, slow, and costly. This paper introduces ongoing research addressing these two fundamental issues. First, by developing an integrated framework for automating manufacturing of reinforced concrete building elements through computation and robotic technology, and second by adapting such framework to the specific technical and socioeconomic contexts of Colombian construction, specifically for social housing.
\end{abstract}

Keywords: non-prismatic concrete elements, reinforced concrete, flexible formwork, parametric modelling, construction in Colombia.

\section{INTRODUCTION}

The construction industry is one of the main sectors in the world economy, representing $13 \%$ of the GDP globally (Barbosa et al., 2017), and in developing countries, it poses important challenges, especially given the need for development of infrastructure and housing.

In terms of sustainability, the construction industry is a major source of carbon. For example, it is responsible for nearly half of the UK's carbon emissions (BIS, 2010). Recent success in reducing operational energy, and the introduction of strict targets for near-zero energy buildings (EC, 2010), means that embodied energy is fast becoming dominant and will soon approach $100 \%$ of whole life energy (Moynihan \& Allwood, 2014). The main culprit is concrete; the world's most widely used man-made material, which accounts for more than $5 \%$ of global $\mathrm{CO} 2$ emissions.

In terms of productivity, construction creates the vast majority of the infrastructure that is essential for trade and commerce; it underpins the productivity of most industries (ClOB, 2016). However, for the construction sector itself, productivity is particularly poor, and concrete construction in particular is labour intensive, slow, and costly. In Colombia in particular, it was found that productivity has actually contracted in recent years, putting the local construction industry index at one of the lowest levels internationally (CAMACOL \& McKinsey Global Institute, 2017). Two of the main reasons are attributed to low design-engineering quality and the lack of adoption of new technologies. This makes automation, and particularly automation of formwork and reinforcement, a crucial first step towards addressing the sector's poor productivity.

As with most developing countries, Colombia is still transitioning from a rural to an urban nation. It is estimated that $76 \%$ of its population lives in cities, and this is projected to rise to $82 \%$ by 2030 . Along with rapid population growth, this brings significant challenges, most importantly the housing deficit and particularly that related to low income families. According to the Colombian Ministry of Housing, based on information from the last population and housing census in 2018, despite recent years government efforts that have reduced housing deficit from $12.5 \%$ to $5.2 \%$, some 600,000 new housing units are still required (Ministerio de Vivienda Ciudad y Territorio de Colombia, 2018). Due to the continuous population growth, it is estimated that 3.2 million units need to be built over the next decade (Bell, 2019). According to last year's construction figures, at least $25 \%$ of these correspond to housing for the most needy, classified as VIS (Vivienda de Interés Social), denoting housing units whose total cost is below the equivalent of $£ 27 \mathrm{k}$ (Departamento Administrativo Nacional de Estadística, 2020b). Looking at the same figures, VIS construction is growing thanks to government policies, even though the general construction industry is in a downward cycle. At the same time, concrete dominates the local construction, representing $34.5 \%$ of all raw materials employed. Pre-mixed concrete consumption in Colombia was $7,274 \mathrm{~m}^{3}$ in 2019 , of which roughly half went to housing construction according to DANE (2020a).

\section{METHODOLOGY}

The authors are currently working on two related research projects, focused on reducing the carbon footprint of the construction industry and increasing productivity.

The first project, titled "Automating Concrete Construction" and known as ACORN (https://automated.construction), is based in the United Kingdom, and will deliver novel computation and robotic technology to enable concrete casting of optimized building elements with minimal human 
involvement, creating end-to-end digital processes to automate the manufacture of such elements. Such approach has the potential to transform building production into an optimised and automated process with better quality control and safety record.

The approach to reducing the amount of concrete used in buildings is the adoption of non-prismatic concrete elements. Traditional formwork methods for concrete result in building elements with a constant cross-section, but the shear forces and bending moments that such elements have to withstand are far from constant along their length, leading to potential reductions in material use of up to $50 \%$ (W. Hawkins et al., 2020; Orr et al., 2011). Current digital design and fabrication methods enable the generation and analysis of customized and complex geometries (Kolarevic, 2004), including non-prismatic concrete elements. However, if such elements are to be used in real construction scenarios, their design, fabrication and construction need to be streamlined and flexible.

With that in mind, computational design tools are being developed, to support designers in adopting non-prismatic concrete elements (beams, columns, slabs) in their building designs. One of the aims of the design tool is its integration with established frameworks, including CAD, BIM and Parametric Modelling tools, thus contributing directly to widespread adoption of the non-prismatic concrete elements in the industry. In parallel, the project is also exploring strategies towards the full automation of the production of concrete elements, by using robotics to create both bespoke formwork and reinforcement. In order to ensure this academic research makes a real difference to the construction industry, the project has proactively engaged with a diverse range of end-users and interest groups to build a community of champions to lead a culture change in the industry.

The focus of this paper is the second project, which is presently in its early stages, and will be looking to adapt solutions from the first to specifically address the challenges of the Colombian construction sector, and in particular for social housing applications. The goal is to reduce the amount of concrete used in Colombian social housing construction, resulting in sustainability and economic benefits. It is important to note that, given the differences in the project contexts, the Colombian work will focus on the hybridization of materials and technologies, finding appropriate solutions that combine both vernacular and novel practices. This project is being carried out in three different stages. The first is dedicated to defining a specific application where the use of novel engineering and technologies of concrete construction can have maximum impact on social housing. This involves interviews with stakeholders from local industry, government and academia, to get feedback on viable applications. In the second stage, initial designs will be developed, software tools from ACORN adapted to the specific Colombian context, and mock-ups will be built to allow structural and constructive testing. In the final stage, the findings will be disseminated to the academic and industry stakeholders internationally, especially those in developing countries like Colombia.

\section{RELATED WORK}

One promising method for efficient production of nonprismatic concrete elements is the use of flexible formwork, and in particular fabric formwork.

The use of fabric formwork for casting concrete dates back to the late $19^{\text {th }}$ century, when Gustav Lilienthal is credited for the first application of fabric formed concrete with his invention of a patented suspended floor system. In the 20th century, fabric formwork has been used both for structural and architectural applications. The work of James de Waller on concrete shell roofs exemplifies the use of fabric formwork for structural purposes, which served as inspiration for some of the works by Felix Candela (Veenendaal et al., 2011). On the other hand, we find examples of architectural applications in the work of Miguel Fisac, who used fabric formwork to imprint distinct surface textures onto concrete façade panels (Veenendaal et al., 2011)

There has been a recent resurgence of interest in developing fabric formed concrete techniques. Notably the Center for Architectural Structures and Technology (C.A.S.T.), led by Mark West at the University of Manitoba, explored the related architectural properties. In contrast, the work of John Orr at University of Bath focused on the structural design of optimized structures. Some of this research is driven in part by the widespread availability of high-strength fabrics and modern computational analysis techniques (W. J. Hawkins et al., 2016).

The integration of computational design techniques, especially parametric modelling for designing precast concrete elements, has been shown to have a positive impact on productivity (Sacks et al., 2004), which is particularly relevant for tackling the challenges facing the Colombian construction sector. One of such challenge is the limited access to digital fabrication technology, which justifies the authors' focus on the hybridization of technologies. Similar limitations have been addressed by studies that focus on low-tech approaches to digital fabrication (Vazquez et al., 2018; Yuan et al., 2013). While both of these studies are applied to brick masonry construction rather than concrete, they highlight the challenges and potential solutions for the use of computational design technologies in areas where advanced digital fabrication methods are not available. That said, simply the ability to gain immediate feedback on the geometric, structural and construction implications of a design decision, a step that not so long ago used to require expensive physical testing, the use of digital technologies by itself can make new possibilities a reality, even for traditional building processes. For example, studies concerning tiled vaults (Rajabzadeh \& Sassone, 2017; Rippmann \& Block, 2013) highlight such possibilities.

\section{DESIGN TOOL DEVELOPMENT}

The production of efficient concrete elements begins with their design. One objective of the ACORN project is therefore to provide an integrated tool to be used in practice within the construction industry, which supports the design of optimized reinforced concrete elements, with a main focus on minimizing embodied carbon, while taking into account all the constraints related to fabrication, transportation and assembly of those elements. Such 
design tool corresponds to a system that allows the evaluation and optimization of the performance of the concrete elements by articulating three modules, namely generation, analysis and optimization, and is informed by manufacturing constraints (Fig. 1). Such constraints derive from the fabrication methods being explored, which include fabric formwork as a special case of flexible formwork. Presently, the adopted optimization approach looks for designs that use just enough material for satisfying their design requirement, and no more.

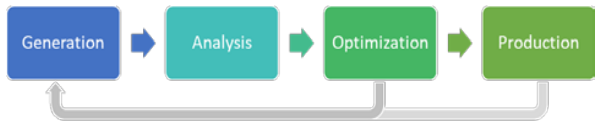

Figure 1: Modules in the ACORN design tool.

The ACORN project is guided by a fail-fast philosophy. Accordingly, initial prototypes of the design tool were implemented on existing parametric modelling applications, namely Grasshopper (Rutten, 2009) and Karamba (Preisinger, 2013), extended through development of customized components. In our design tool, the shape of concrete elements is represented by NURBS surfaces by default, although in the analysis module such surfaces are converted into meshes for the purpose of Finite Element Analysis.

Presently, development of the design tool has focused on the generation and analysis modules, and on two types of concrete elements: beams and floor slabs. While the generation module is responsible for defining a design space of solutions, the analysis module evaluates those solutions against the project's objectives. Whilst, the parameter values in the generation are currently set directly, they will subsequently be governed by the optimization module.

\section{BEAMS}

The model of non-prismatic RC beams is parametrically generated by the design tool from a set of input values and its shape is represented by NURBS geometry. Arguably, the most relevant inputs are those that define the beam's variable cross section. Given the predominance of prismatic beams in construction, existing structural design tools typically represent beams with a single cross section. In our tool, the representation strategy for non-prismatic beams relies in the use of variable cross sections along the beam's length, complying with the Euler-Bernoulli beam theory, according to which the cross-section of a beam remains plane after deformation (Bauchau \& Craig, 2009). Since existing tools provide limited support for nonprismatic beams, custom components have been implemented in C\#, as part of a prototype Grasshopper plugin oriented at both the generation and the analysis modules.

Presently, two templates are implemented, capable of generating T-shaped, and fabric-formed (FF-) beams. Tbeams were selected for their widespread use in construction, as well as for the geometric simplicity of their shape, which makes it easy to parametrize. Therefore, it provides a base-line for the implementation of additional beam types later. For example, standard rectangular beams can also be generated using the T-beam template, by setting the width of the down-stand web to be equal to the width of the top-flange. The choice for FF-beams derives from their potential for efficient use of material, as well as from the project team members' existing familiarity with their design and construction. To define the cross section of FF-beams, the software applies iterative formfinding methods that take into account the effects of both gravity and the hydrostatic pressure of the poured liquid concrete. Such methods calculate variations of the 'elastica' curve, given its top width and depth as inputs (Foster, 2010; Tayfur et al., 2016), as well as being able to determine the shape of fabric formwork when restrained with internal ties (Kostova et al., 2016). These methods are capable of generating many variations of form-found designs for FF-beams, as shown in Figure 2.

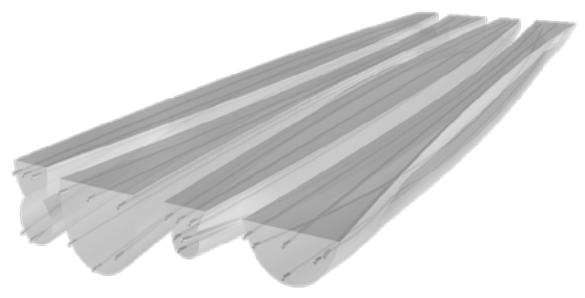

Figure 2: Four RC beam designs generated by the software tool.

Subsequently, such designs can be analysed by our tool in terms of their structural performance. In the case of beams, performance is assessed by the analysis module in regard to serviceability, particularly in terms of deflection, which is estimated using the method of integration of curves (Visintin et al., 2013), as previously applied in the scope of non-prismatic RC beams (Tayfur et al., 2016). This method estimates the displacement at different points along the beam, by doubly integrating curvature of the varying crosssection at those points. Curvature for each cross section is extracted from a moment-curvature plot by applying the current value for bending moment, generated by an iterative numerical method, where equilibrium forces and resulting resisting moments are determined for a range of strain diagrams (Figure 3 ).

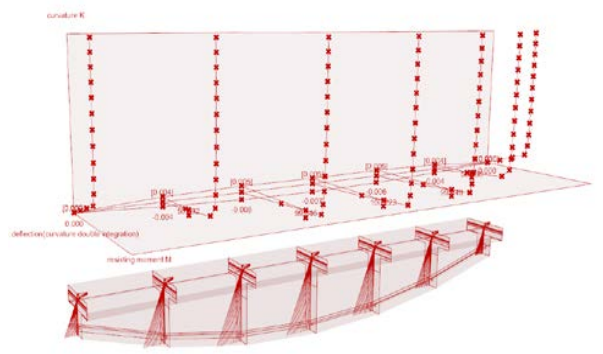

Figure 3: Analysis diagram for a non-prismatic T-beam

The main advantage of the implemented analysis module over existing structural (finite element) analysis solutions such as Karamba (Preisinger, 2013), is its ability to analyse non-prismatic geometry, as well as taking reinforcement 
steel into account. Nevertheless, Karamba was useful initially to validate force and moment diagrams.

Following the development of the generation and analysis modules, a third module will be responsible for optimizing the shape of non-prismatic beams towards minimizing the volume of concrete, which is enabled by variable cross section. Such objective can be achieved by optimizing individual cross section closer to their maximum utilization, and thus avoiding overdimensioning.

\section{FLOOR SLABS}

The second type of concrete elements being studied are floor slabs, in particular, thin concrete shells. Previous research has shown that thin shells can be used for building more sustainable reinforced concrete floor slabs (Hawkins et al., 2020). In this case, the thin shell provides the structural load transfer, whereas a non-structural in-fill provides a level top surface.

As with non-prismatic beams, the generation module of the software tool is responsible for defining the shape of the slab, particularly focusing on the thin concrete shell that supports it. Departing from the research of Hawkins et. al. (2020), development of the generation module began by implementing a parametric model for groin vaults (Figure 4). Their shape depends on geometric parameters such as span, height and thickness, while additional parameters pertaining to material properties and boundary conditions and loads also determine its performance. Currently, the shells have a constant thickness, but are nevertheless considered to be 'non-prismatic' due to their complex geometry. In future, the authors will extend their studies to variable thickness shells to assess its potential to reduce concrete volumes even more.

Since one of the advantages of using concrete thin shells is their efficiency in working in compression, the analysis module (currently using Karamba) evaluates shell performance in terms of tensile stress and bending energy, which can be used subsequently as optimization objectives.

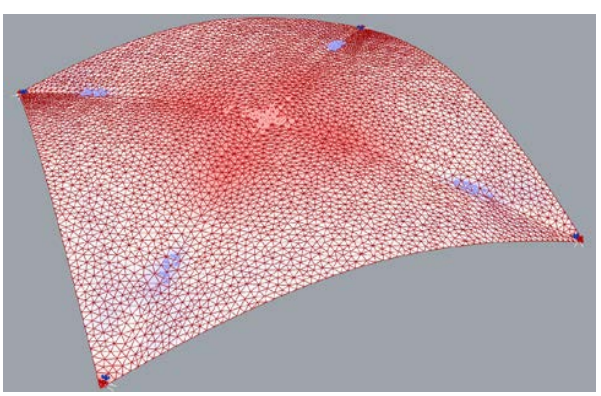

Figure 4: Analysis of a groin vault thin shell

In order to better understand the structural behaviour of the generated floor slabs, and also to validate the analysis module, a series of parametric studies have been conducted. For that purpose, the tool integrates a module that enables the visualization of analysis results as twoand three-dimensional graphs (Figure 5), which should prove useful as the number of design variables increases.
In terms of minimizing embodied carbon, the use of thin shells for construction of concrete floor slabs by itself has been shown to entail a significant reduction in concrete volume, leading to embodied carbon reductions of more than $50 \%$ when compared to flat concrete slabs, as well as self-weight reductions of $43-53 \%$, which would save additional material in columns and foundations (Hawkins et al., 2020). Additionally, we aim to reduce the amount of reinforcement, which, depending on the material, can also have a large impact on the embodied carbon in the slab. Whilst the software currently uses the volume of concrete as a proxy for embodied carbon, ACORN is carrying out a study into the Whole Life Cost of such innovative concrete structures. The authors therefore plan to replace volumeof-concrete with Whole Life Carbon (WLC) as the optimization objective in the near future.

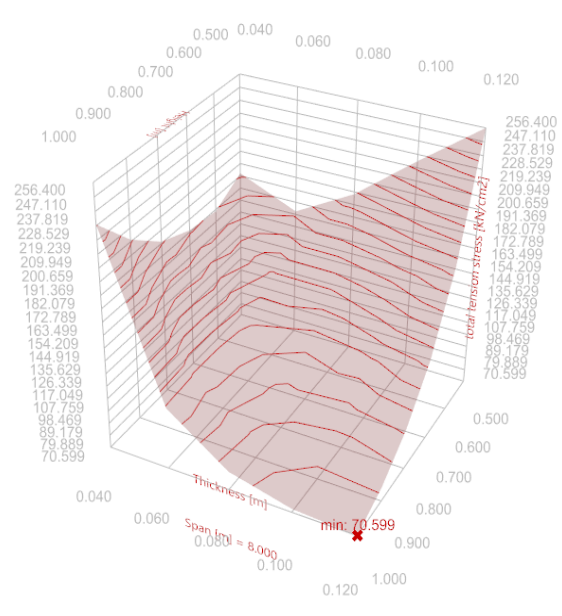

Figure 5: Visualization of analysis results in 3D graphs

\section{DISCUSSION}

The proposed design tool integrates iterative optimization processes within a parametric modelling framework, to generate optimal (non-prismatic) forms for concrete elements. While the focus has been on the structural performance of concrete elements, their optimization in terms of embodied carbon should take into consideration not only in the materials that compose them, but also the contributions from manufacturing, transportation and assembly (cradle-to-gate).

Such construction-related constraints are greatly dependent on local contexts. The ACORN design tool is principally being developed within a UK context to deliver fully automated manufacturing of optimized concrete elements. This project will therefore need to customize the tool for use in a Colombian context. For example, adapting to scenarios where robots are not available, and readjusting the WLC objective function to reflect regional differences in materials, costs and construction practices. Local building codes and structural requirements will differ for a particular building type (such as social housing), as will the type of transportation used for carrying pre-cast concrete elements to the building site and the methods and tools used for their assembly. 
An advantage, therefore, of having to consider two different contexts (UK and Colombia) in the development of the design tool, is the potential for rendering it more flexible and more broadly applicable.

By incorporating locally-driven real-world constraints in a user-friendly software framework, a significant reduction in concrete-use can be delivered, leading to a more cost effective and sustainable construction. In the case of Colombian social housing, even though this project is still in its very early stages, the use of floor slab applications seems particularly promising and could have a major impact. For example, in the year preceding February 2020, 144 housing projects were initiated in Colombia, comprising a total of 19,556 units, which gives an average of 135 units per housing project (CAMACOL, 2020, p. 35). Since VIS projects are normally the largest, with developments of up to 2,000 units at a time, it seems that just as much effort should be given to improving the design processes as to reducing the amount of concrete.

A comparative study of costs for the three most common material systems used for social housing construction in Colombia (Carrillo León et al., 2015) shows that even if raw materials for brick masonry are cheaper, their overall cost is higher than concrete systems, due to shorter and more efficient erection processes for concrete (see Table 1). This suggests a potential benefit by embedding cheaper materials into prefabricated concrete elements to gain the best of both systems.

Table 1: Material system cost comparison: values relative to the legal minimum wage (adapted from Carrillo León et al., 2015).

\begin{tabular}{|c|c|c|c|c|}
\hline & & $\begin{array}{l}\text { Confined } \\
\text { masonry }\end{array}$ & $\begin{array}{r}\text { Reinforced } \\
\text { concrete }\end{array}$ & $\begin{array}{r}\text { Steel fibre } \\
\text { reinforced } \\
\text { concrete }\end{array}$ \\
\hline \multirow{2}{*}{$\begin{array}{l}\text { Masonry } \\
\text { elements }\end{array}$} & Structural & 21.890 & 0 & 0 \\
\hline & $\begin{array}{l}\text { Non- } \\
\text { structural }\end{array}$ & 0.299 & 0 & 0 \\
\hline \multirow{2}{*}{$\begin{array}{l}\text { Concrete } \\
\text { elements }\end{array}$} & Structural & 9.506 & 27.956 & 29.202 \\
\hline & $\begin{array}{l}\text { Non- } \\
\text { structural }\end{array}$ & 4.286 & 0.735 & 1.035 \\
\hline \multicolumn{2}{|c|}{ Total material cost } & 35.981 & 28.691 & 30.237 \\
\hline
\end{tabular}

In Colombia there is a long tradition of brick masonry construction, and its use, normally in combination with concrete reinforcement elements, represents two-thirds of the built area of the country's total construction, with only a slightly lower proportion when looking at housing only (Departamento Administrativo Nacional de Estadística, 2017 , p. 25). Besides the potential exhibited by the studies cited above, the combination of brick and concrete has been used historically in Colombia in a number of different ways (López López et al., 2019). Accordingly, brick and tile masonry can be seen as the natural material option for hybridization with the modern concrete methods of ACORN.

Due to various legal and economic factors, most social housing projects in Colombia are constructed as low-rise buildings (usually 4 to 5 floors), where load-bearing walls are combined with slabs avoiding the need for more robust skeletal structures and the punctual loads associated to them. In this context, the use of hybrid shell structures, both for slab and wall applications, may generate new and interesting possibilities.

\section{CONCLUSION}

This paper presents current research landscape for minimizing the environmental impact of concrete construction. In particular, it introduced the ACORN project, and its early development of a design tool for promoting the adoption by the construction industry of non-prismatic concrete building elements. While the initial development has focused on the optimization of structural performance and minimization of material, a number of constraints and optimisation objectives are being added in order to extend its relevance. In particular, a set of fabrication constraints pertaining to automating the manufacturing of concrete elements will be derived from the current experimental work being explored.

These constraints are also to be adapted to the context of social housing in Colombia, where access to automation in construction is more limited. Such an adaptation, involving different technical and economic contexts, will serve as a case study for informing similar future adaptations to different cultural and socio-economic contexts. This will enable Colombia, and similar developing countries, to benefit from the significant investment and research effort being undertaken as part of ACORN.

\section{ACKNOWLEDGEMENTS}

The research described in this paper has been funded by UKRI under their Transforming Construction programme (grant number EP/S031316/1) and by the Royal Academy of Engineering's Transforming Systems through Partnerships programme (grant number TSP/1404)

\section{REFERENCES}

Barbosa, F., Woetzel, J., Mischke, J., Ribeirinho, M. J., Sridhar, M., Parsons, M., Bertram, N., \& Brown, S. (2017). Reinventing Construction.

Bauchau, O. A., \& Craig, J. I. (2009). Euler-Bernoulli beam theory (pp. 173-221). https://doi.org/10.1007/978-90-481-251665

Bell, J. G. (2019). "En Colombia se deben construir 3,2 millones de vivienda en la siguiente década", Camacol. Editorial La República. https://www.larepublica.co/economia/colombiase-deben-construir-32-millones-de-vivienda-en-lasiguiente-decada-camacol-2902162

CAMACOL. (2020). Coordenada Urbana: Actividad Edificadora Segmento Residencial y No Residencial. In Informe de coyuntura Marzo de 2020.

CAMACOL, \& McKinsey Global Institute. (2017). Una apuesta en construcción: mayor productividad, menores riesgos. In Congreso Colombiano de la Construcción 2017. https://camacol.co/sites/default/files/McKinsey Global Institute_0.pdf

Carrillo León, J., Echeverri Quintero, F., \& Aperador Chaparro, W. (2015). Evaluación de los costos de construcción de sistemas estructurales para viviendas de baja altura y de interés social. Ingeniería, Investigación y Tecnología, 16(4), 479-490. https://doi.org/10.1016/j.riit.2015.09.001

Departamento Administrativo Nacional de Estadística. (2017). Boletín Técnico, Censo de Edificaciones I Trimestre de 2017.

https://www.dane.gov.co/files/investigaciones/boletines/ce ed/bol_ceed_Itrim17.pdf 
Departamento Administrativo Nacional de Estadística. (2020a). Estadísticas de concreto premezclado (EC). https://www.dane.gov.co/index.php/estadisticas-portema/construccion/estadisticas-de-concreto-premezclado

Departamento Administrativo Nacional de Estadística. (2020b). Vivienda VIS $y$ NO https://www.dane.gov.co/index.php/estadisticas-portema/construccion/vivienda-vis-y-no-vis

Foster, R. (2010). Form Finding And Analysis Of Fabric Formed Concrete Beams [University of Bath]. https://espace.library.uq.edu.au/view/UQ:689900

Hawkins, W. J., Herrmann, M., Ibell, T. J., Kromoser, B., Michaelski, A., Orr, J. J., Pedreschi, R., Pronk, A., Schipper, H. R., Shepherd, P., Veenendaal, D., Wansdronk, R., \& West, M. (2016). Flexible formwork technologies - a state of the art review. Structural Concrete, 17(6), 911-935. https://doi.org/10.1002/suco.201600117

Hawkins, W., Orr, J., Ibell, T., \& Shepherd, P. (2020). A design methodology to reduce the embodied carbon of concrete buildings using thin-shell floors. Engineering Structures, 207, 110195. https://doi.org/10.1016/j.engstruct.2020.110195

Kolarevic, B. (2004). Architecture in the Digital Age: Design and Manufacturing. In Architecture in the Digital Age: Design and Manufacturing. Taylor \& Francis. https://doi.org/10.4324/9780203634561

Kostova, K., Ibell, T., Darby, A., \& Evernden, M. (2016). Using fabric to shape appropriate concrete structures (p. S174). https://researchportal.bath.ac.uk/en/publications/usingfabric-to-shape-appropriate-concrete-structures

López López, D., Van Mele, T., \& Block, P. (2019). The combination of tile vaults with reinforcement and concrete. International Journal of Architectural Heritage, 13(6), 782798. https://doi.org/10.1080/15583058.2018.1476606

Ministerio de Vivienda Ciudad y Territorio de Colombia. (2018). Colombia superó la meta del déficit habitacional consignada en el Plan Nacional de Desarrollo. http://www.minvivienda.gov.co/sala-deprensa/noticias/2018/abril/colombia-supero-la-meta-deldeficit-habitacional-consignada-en-el-plan-nacional-dedesarrollo

Orr, J. J., Darby, A. P., Ibell, T. J., Evernden, M. C., \& Otlet, M. (2011). Concrete structures using fabric formwork. The Structural Engineer, 89(8), 20-26. https://researchportal.bath.ac.uk/en/publications/concretestructures-using-fabric-formwork

Preisinger, C. (2013). Linking structure and parametric geometry. Architectural Design, 83(2), 110-113. https://doi.org/10.1002/ad.1564

Rajabzadeh, S., \& Sassone, M. (2017). Brick Patterning on FreeForm Surfaces. Nexus Network Journal, 19(1), 5-25. https://doi.org/10.1007/s00004-016-0305-9

Rippmann, M., \& Block, P. (2013). Funicular Shell Design Exploration. Adaptive Architecture [Proceedings of the 33rd Annual Conference of the Association for Computer Aided Design in Architecture (ACADIA), 337-346. https://www.researchgate.net/publication/271995309_Funi cular_Shell_Design_Exploration

Rutten, D. (2009). Grasshopper. https://www.grasshopper3d.com/

Sacks, R., Eastman, C. M., \& Lee, G. (2004). Parametric 3D modeling in building construction with examples from precast concrete. Automation in Construction, 13(3), 291312. https://doi.org/10.1016/S0926-5805(03)00043-8

Tayfur, Y., Darby, A., Ibell, T., Evernden, M., \& Orr, J. (2016). Serviceability of fabric-formed concrete structures. International Journal of Civil, Environmental, Structural, Construction and Architectural Engineering, 10(5), 537542

https://researchportal.bath.ac.uk/en/publications/serviceabi lity-of-fabric-formed-concrete-structures

Vazquez, E., Diarte, J., \& Gursoy, B. (2018). Bridging Parametric Design and Craftmanship: Materializing the Digital Parametric Wall with Low-tech Masonry Construction Techniques. Proceedings of the 23rd International Conference of the Association for Computer-Aided Architectural Design Research in Asia CAADRIA 2018. https://www.researchgate.net/profile/Julio_Diarte/publicatio n/325478157 Bridging Parametric Design and Craftman ship_Materializing_the_Digital_Parametric_Wall_with_Low

tech Masonry Construction Techniques/links/5b1065f8ac a2723d9978c6d2/Bridging-Parametric-

Veenendaal, D., Coenders, J., Vambersky, J., \& West, M. (2011). Design and optimization of fabric-formed beams and trusses: Evolutionary algorithms and form-finding. Structural Concrete, 12(4), 241-254. https://doi.org/10.1002/suco.201100020

Visintin, P., Oehlers, D. J., Muhamad, R., \& Wu, C. (2013). Partialinteraction short term serviceability deflection of RC beams. Engineering Structures, 56, 993-1006. https://doi.org/10.1016/J.ENGSTRUCT.2013.06.021

Yuan, P. F., Zhang, M., \& Han, L. (2013). Low-Tech Digital Fabrication: Traditional Brick as Material in Digital Practice (pp. 139-148). Springer, Berlin, Heidelberg. https://doi.org/10.1007/978-3-642-38974-0_13 